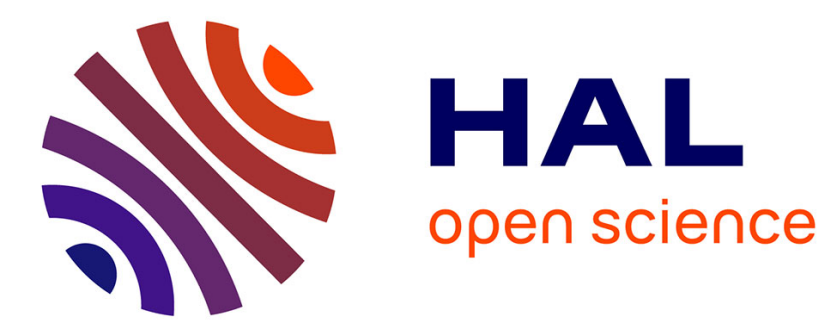

\title{
Resonances in Receiving Two-Arm Spiral Antennas
}

\author{
Naga Devarapalli, Israel Hinostroza, Regis Guinvarcrh, Randy Haupt
}

\section{To cite this version:}

Naga Devarapalli, Israel Hinostroza, Regis Guinvarcrh, Randy Haupt. Resonances in Receiving TwoArm Spiral Antennas. 2018 IEEE-APS Topical Conference on Antennas and Propagation in Wireless Communications (APWC), Sep 2018, Cartagena des Indias, Colombia. 10.1109/apwc.2018.8503796 . hal-02124613

\section{HAL Id: hal-02124613 \\ https://hal-centralesupelec.archives-ouvertes.fr/hal-02124613}

Submitted on 29 Mar 2021

HAL is a multi-disciplinary open access archive for the deposit and dissemination of scientific research documents, whether they are published or not. The documents may come from teaching and research institutions in France or abroad, or from public or private research centers.
L'archive ouverte pluridisciplinaire HAL, est destinée au dépôt et à la diffusion de documents scientifiques de niveau recherche, publiés ou non, émanant des établissements d'enseignement et de recherche français ou étrangers, des laboratoires publics ou privés. 


\section{Resonances in Receiving Two-Arm Spiral Antennas}

\author{
Naga R. K. Devarapalli \\ Mahindra École Centrale \\ Hyderabad, India \\ nrdevara@gmail.com
}

\author{
Israel Hinostroza \\ SONDRA \\ CentraleSupélec \\ Gif-sur-Yvette, France \\ israel.hinostroza@centralesupelec.fr \\ Randy L. Haupt \\ Electrical Engineering of Computer \\ Science \\ Colorado School of Mines \\ Golden, Colorado, USA \\ rhaupt@ieee.org
}

\author{
Régis Guinvarc'h \\ SONDRA \\ CentraleSupélec \\ Gif-sur-Yvette, France \\ regis.guinvarch@centralesupelec.fr
}

\begin{abstract}
A planar array of symmetrical square spiral antennas over a ground plane have resonances when scanning off-broadside. This paper demonstrates that resonances also appear in a single symmetrical receiving spiral antenna without a ground plane, provided that the incident wave is offbroadside. Transmission line analysis predicts the resonances.
\end{abstract}

Keywords—planar array, spiral antennas, resonances, transmission line model.

\section{INTRODUCTION}

At certain frequencies, a planar array of symmetrical square spiral antennas over a ground plane is not effective for scanning off-broadside [1]. These frequencies are termed as resonances and the current distribution on the arms of the spirals forms a strong standing wave pattern. A spiral antenna becomes resonant at a frequency when the lengths of its arms are multiples of half the resonant wavelength. It has been observed that mutual coupling between the array elements contributes to these resonances [1]. The idea of a "spoiled" spiral (arms with a slight asymmetry in terms of length) was suggested in [1] for suppressing resonances. A lossless transmission line model was then proposed in [2] to explain the resonances in a spiral antenna in an array with a ground plane. The model was also used to verify that a perfect standing wave may not be set up on a spoiled spiral.

We show here that even a single symmetrical spiral antenna without a ground plane, in the receiving mode, may become resonant when the lengths of its arms are multiples of half the corresponding wavelength. Therefore, there does not seem to be a fundamental requirement for the presence of a ground plane or for a spiral to be in an array configuration. In fact, resonances have also been observed in spirals of various shapes. There is a standing wave current distribution setup on resonant spiral antennas, with the incident wave offbroadside, impeding the receiving capability of the antennas.

\section{RESONANCES ON A SINGLE SPIRAL ANTENNA WITHOUT GROUND PLANE}

Fig. 1 shows a single two-arm symmetrical square spiral antenna in the receiving mode. The spiral is terminated in a load ZL at the center. If a linearly polarized plane wave illuminates the antenna along the plane of the spiral a current distribution is induced along the arms of the antenna. The spiral shown in the configuration in Fig. 1 becomes resonant when the incident fields satisfy any of the criteria in (1) or (2).

$$
\begin{aligned}
& \mathbf{E}_{1} \neq 0 \quad \& \quad \mathbf{E}_{2}=0 \\
& \mathbf{E}_{1}=0 \& \mathbf{E}_{2} \neq 0
\end{aligned}
$$

$\mathbf{E}_{1}$ and $\mathbf{k}_{1}$ ( $\mathbf{E}_{2}$ and $\mathbf{k}_{\mathbf{2}}$ ) correspond to electric-field and propagation vectors of an incident plane wave.

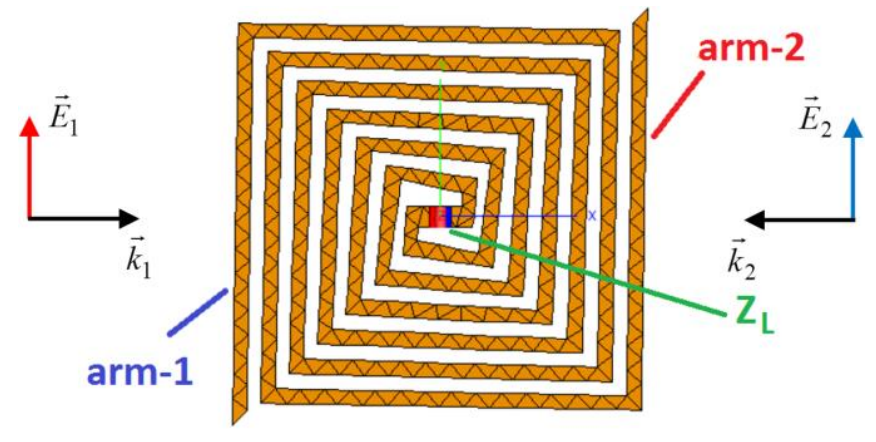

Fig. 1. Symmetrical square spiral illuminated by two plane waves.

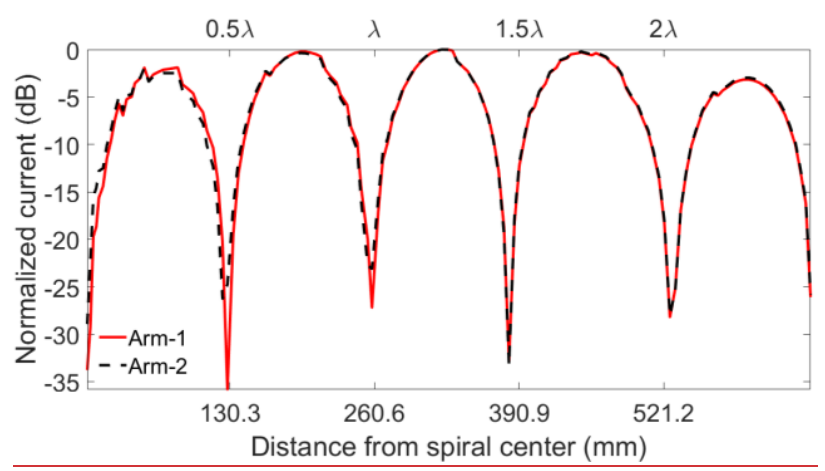

(a) Resonant square spiral at $1.15 \mathrm{GHz}$

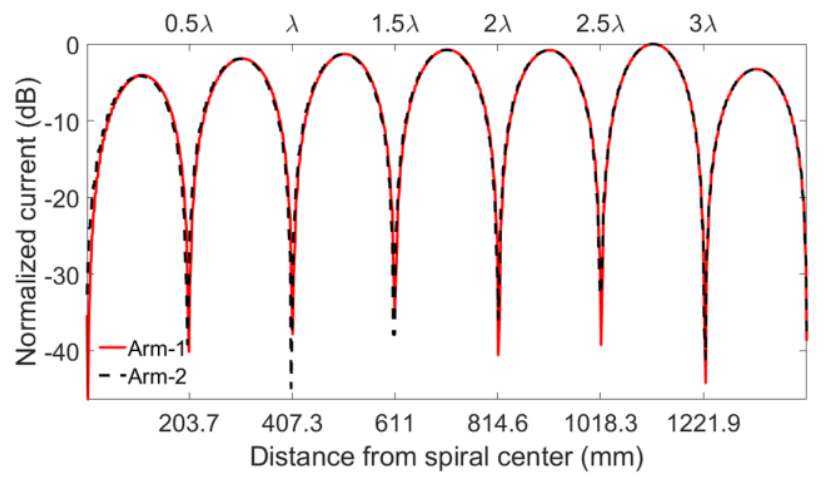

(b) Resonant Archimedean spiral at $0.73 \mathrm{GHz}$

Fig. 2. Symmetrical square spiral illuminated by two plane waves.

Taking the center of a spiral as a reference, the plots in Fig. 2 show the amplitude of surface current along the length of an arm on two different resonant two-arm symmetrical spiral antennas. Fig. 2a corresponds to the square spiral antenna in Fig. 1 resonating at $1.15 \mathrm{GHz}$. It was simulated 
using a full-wave solver, FEKO, and constructed from a perfect electrically conducting surface. Note that Fig. 2a remains the same irrespective of which criteria are used among (1) or (2). Similar resonances are observed in other kinds of individual spiral antennas, such as Archimedean spirals, as shown in Fig. 2 b.

Simulations show that the spiral becomes resonant when the impinging plane wave is off-broadside and when the lengths of the arms are multiples of half the corresponding wavelength associated with the incident frequency. Moreover, the resonances are strongest when the wave's propagation and electric-field vectors are parallel to the plane of the spiral.

Table I shows geometrical dimensions and resonant frequencies considering two types of resonant two-arm symmetrical spiral antennas without a ground plane, where $f$ is a resonant frequency in $\mathrm{GHz}, l$ is the length of each spiral arm in $\mathrm{mm}, l_{\lambda}$ is the spiral arm length in multiples of the freespace wavelength $(\lambda)$ corresponding to the resonant frequency and $w$ is the width of each spiral arm in $\mathrm{mm}$.

TABLE I. GEOMETRICAL DIMENSIONS AND RESONANT FREQUENCIES CONSIDERED FOR VARIOUS SYMMETRICAL SPIRAL ANTENNAS

\begin{tabular}{|c|c|c|}
\hline Spiral & Square & Archimedean \\
\hline$f(\mathrm{GHz})$ & 1.15 & 0.73 \\
\hline$l(\mathrm{~mm})$ & 653.2 & 1426.6 \\
\hline$l_{\lambda}$ & 2.5 & 3.5 \\
\hline$w(\mathrm{~mm})$ & 3.4 & 2.7 \\
\hline
\end{tabular}

The load impedance at the feed-terminals of the spirals is $220 \Omega$. Note that the resonance phenomenon in Fig. 2, for a single spiral antenna without a ground plane, is very similar to the ones reported in [1] and [2] for planar arrays of symmetrical square spiral antennas over a ground plane.

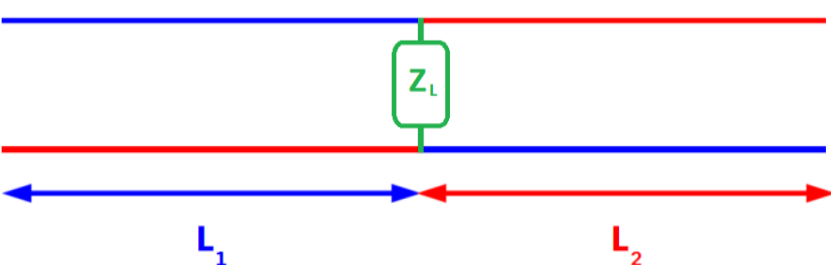

Fig. 3. Double transmission line model of spiral antenna of Fig. 1. Blue and red colors correspond to arm 1 and 2, respectively. L represents the arm lengths of the spiral.

To model the resonances, we have considered a double transmission line model, which has the same geometry as in [2]. If the arms of the spiral of Fig. 1 are unwrapped, considering the proximity between the arms, we obtain a double transmission line model without the need of an actual ground plane (see Fig. 3). Blue and red colors represent the arms 1 and 2 and the load ZL at the center is in green. However, the transmission lines in our model are considered to be lossy. Even after using the lossy transmission line model, we have obtained the same criteria required for the spiral to become resonant.

\section{CONClusions}

Our analysis is helpful in explaining the resonances that appear in receiving spiral antennas even without a ground plane, when the incident field is off-broadside. Resonances are observed in two kinds of individual spirals and are a fundamental characteristic of the element itself. Our analysis is also consistent with previous works, which show that a spoiled spiral is helpful in suppressing strong resonant behavior.

\section{REFERENCES}

[1] H. Steyskal, J. Ramprecht, and H. Holter, "Spiral elements for broadband phased arrays," IEEE Transactions on Antennas and Propagation, vol. 53, no. 8, pp. 2558-2562, Aug 2005.

[2] J. C. West and H. Steyskal, "Analysis and feeding of a spiral element used in a planar array," IEEE Transactions on Antennas and Propagation, vol. 57, no. 7, pp. 1931-1935, July 2009. 